\title{
Association of seeking ophthalmic assessment in children with parental history of refractive errors
}

\author{
Muhammad Zahid Latif ${ }^{1}$, Muhammad Athar Khan², \\ Saira Afzal ${ }^{3}$, Syed Amir Gilani ${ }^{4}$
}

\begin{abstract}
Objective: To find out the association of seeking ophthalmic assessment in children with parental history of refractive errors.

Methods: After the approval of ethical review board, an analytical cross-sectional study was conducted in eight high schools of public and private sector at Lahore during the period of seven months from August 2017 to March 2018. Multistage random sampling technique was opted and 2000 study subjects were recruited including $50 \%$ boys and $50 \%$ girls. Informed consent was obtained and data was collected on a structured questionnaire. The data was organized, entered in version 23 of IBM SPSS and analyzed by the use of statistical tools.

Results: Age of the respondents ranged between nine to 18 years with a mean of $13.40 \pm 1.82$ SD. Parental history of wearing spectacles was present in $21.3 \%$ of the fathers and $28.6 \%$ of the mothers. Moreover, $72.4 \%$ of the participants never visited eye care professional. Among private schools, an association was found between the visit of boys to eye care professional and maternal positive history of wearing spectacles ( $p$-value 0.019). A significant association was found between the positive paternal history of wearing spectacles and visit of the female strudy subjects to an eye care professional ( $p$-value 0.001). In public schools, there was an association between visit of children to eye care services and positive history of mothers about the use of spectacles ( $p$-value 0.018 ).
\end{abstract}

Conclusions: This study concludes that positive maternal history of wearing spectacles is associated with the ophthalmic examination of children in both public and private school.

KEYWORDS: Astigmatism, Myopia, Ophthalmic examination, Refractive Errors, School children.

How to cite this:

doi: https://doi.org/10.12669/pjms.35.3.1010

Latif MZ, Khan MA, Afzal S, Gilani SA. Association of seeking ophthalmic assessment in children with parental history of refractive errors. Pak J Med Sci. 2019;35(3):743-748. doi: https://doi.org/10.12669/pjms.35.3.1010

This is an Open Access article distributed under the terms of the Creative Commons Attribution License (http://creativecommons.org/licenses/by/3.0), which permits unrestricted use, distribution, and reproduction in any medium, provided the original work is properly cited.

\section{INTRODUCTION}

Refractive errors are a significant challenge for public health and considered as the commonest ophthalmic problem. ${ }^{1}$ Globally, around 259

Correspondence:

Dr. Muhammad Zahid Latif,

Professor of Community Medicine \& Director

Department of Medical Education,

Azra Naheed Medical College,

The Superior University,

17- KM Raiwind Road,

Lahore, Pakistan.

Email: mzahidlatif@yahoo.com

* Received for Publication:

* Revision Received:

* Revision Accepted:
September 26, 2018

March 19, 2019

March 23, 2019 million people are visually impaired including 98 million having refractive errors. ${ }^{2}$ Refractive errors are the most common reason for the visit of an individual to eye care professional and $43 \%$ of the total visual impairment is due to refractive errors. $^{3}$ Children are the most common victim and these errors are directly linked with poor quality of life, nutritional deficiencies, educational achievements and economic loss. ${ }^{4}$ However, the solution for this problem is a low-cost health 
care intervention and $80 \%$ of the causes of visual impairment can be prevented or treated to avoid blindness. ${ }^{5}$ The available literature identifies that a significant number of Pakistani school children are suffering from the refractive errors. A relevant study concluded that every $5^{\text {th }}$ school going child is having a visual disability in the form of refractive errors in Pakistan. ${ }^{6}$

Different reasons for the non-correction of refractive errors have been concluded in literature. It includes poor knowledge of the issue, lack of services, affordability and accessibility. The economically viable communities with undetected or uncorrected refractive errors in children have also been reported. ${ }^{7}$ Bonnie Keaton found in his study that around $80 \%$ of children in preschool age never receive an ophthalmic examination. Major barriers concluded through this research include inconvenience, unawareness and attitude of parents for eye care. ${ }^{8}$ The study described the attitude of parents as the leading problem to seek eye care services for the children. This means affordability, accessibility and approach to the ophthalmic facilities are relevant issues but changing the affective domain of parents for ophthalmic examination of children is still a problem. Another research revealed that the support of parents is a massive issue for visual screening. This study concluded that after around eighteen months of referral, the parents get the child examined by an eye specialist. ${ }^{9}$ On the other side, this is based on evidence that positive family history of refractive errors enables parents to pursue for the ophthalmic examination and care of the children..$^{10}$ It is also important to mention that the genetic contribution is a major factor regarding the etiology of refractive errors. So, parental attitude towards ophthalmic care should be considered as a key component to improve the visual screening drives in children.

Apart from the financial resources, accessibility, relevant awareness, preventive practices adopted by parents, visual aids and provision of nutritional supplements are fundamental steps for prevention of blindness in the children. It is worth mentioning that parents work hard and remain committed to uplift and educate their children. However, ignoring the vital component of visual screening is an important question mark. The relevant literature about parental history of spectacles and ophthalmic examination of their children especially in Pakistani context is scarce. In view of the above-mentioned scenario, this study was designed and conducted to find out the association between parental history of wearing spectacles and ophthalmic assessment of the children.

\section{METHODS}

An analytical cross-sectional study was conducted in eight high schools of public and private sector at Lahore Pakistan during the period of seven months from August 2017 to March 2018. The study was ethically approved by the Institutional Ethical Review Board (IERB) of The University of Lahore. Multistage random sampling technique was used. ${ }^{11}$ Out of the five Tehsils, one was randomly selected, a list of the number of union councils (UC) in the selected Tehsil was obtained and one UC in urban setting and one UC from rural setting were randomly selected. Later, a list of both public and private high schools in both the UCs was obtained and four public and four private schools from both settings were included in the study. Fifty students of class 6 to class 10 were included whereas the students of other classes were excluded from the study. The sample size was calculated by the Open Epi Tool Kit and following formula was used; ${ }^{12}$

$$
\begin{aligned}
& \text { a Level of significance } \quad 95.00 \% \\
& \text { P1 Expected Proportion of 20.00\% }{ }^{6} \\
& \frac{n=Z_{1} \alpha / 2 P(1-P)}{d^{2}}
\end{aligned}
$$

n Sample size in one group

The estimated sample size for each group was 171 study subjects. However, to increase the strength, accuracy and precision, 250 subjects were included in each group leading to a total of 2000 study subjects. The distribution of the study subjects is presented in Fig.1.

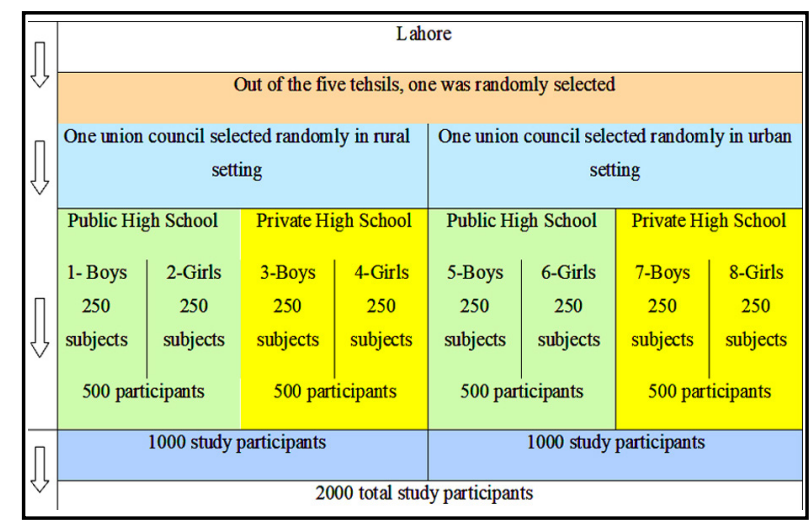

Fig.1: Flow diagram showing the selection of study subjects. 
Screening of refractive errors, according to the defined protocols with required instruments (Snellen charts, refraction boxes with trial frames, autorefractometer, retinoscope, ophthalmoscope and hand-held slit lamp etc.) and logistics by a team of optometrists supervised by an ophthalmologist was managed in the schools. ${ }^{13}$ Visual Acuity (VA) of the study subjects was evaluated with the Standard Snellen Chart placed at a distance of six meters. Students with VA less than 6/9 in the better eye or both eyes were tested for the presence of refractive error by a pinhole. The improvement of the vision with pinhole examination was followed by auto and subjective refraction. It was also cross-checked by retinoscopy. Data was collected on a self-structured questionnaire which consisted of different parts, including basic profile of the participants, relevant family history, ever visit to an eye care professional for visual assessment, ophthalmic examination, VA, best correction, diagnosis and type of refraction. The questionnaire was discussed with experts in ophthalmology to ensure its validity and also pretested for reliability. Informed consent was obtained from the study subjects and permission of parents was also ensured through the school administrations.

The collected data was organized and entered in version 23 of the software Statistical Package for Social Sciences (SPSS). The data was analyzed by using the Chi-square test and a p-value of $\leq 0.05$ was considered as significant.

\section{RESULTS}

There were 2000 subjects with a mean age of 13.40 $\pm 1.82 \mathrm{SD}$ (range: 9 - 18 years). The overall prevalence of refractive errors calculated in this study was $20.6 \%$. Myopia was the leading type $52.2 \%$ followed by Astigmatism 33\% and Hypermetropia 14.8\% respectively. The history of wearing spectacles among parents of the study subjects was studied and found that it was positive in $21.3 \%$ of the fathers and $28.6 \%$ of the mothers. Similarly, any visit of the study subjects to an eye care professional for ophthalmic examination or vision testing was investigated. It was found that $72.4 \%$ of the study participants never visited ophthalmic services for clinical examination.

The parental history of the use of spectacles and ever visit of the study subjects to eye care professional for ophthalmic assessment among the private schools were compared and results are presented in Table-I. The findings represent that there was no association between the studied variables. However, a significant association was found between the positive maternal history of the use of spectacles and ever visit of the male study subjects to an eye care professional (p-value 0.019). These male study participants were not having refractive errors (Table-I). A significant association

Table-I: Comparison of Private school students according to the parental history of wearing spectacles and student's visit to eye care professional.

\begin{tabular}{|c|c|c|c|c|c|c|c|c|}
\hline \multirow{2}{*}{ Gender } & \multirow{2}{*}{$\begin{array}{l}\text { Refractive } \\
\text { Error }\end{array}$} & \multirow{2}{*}{$\begin{array}{l}\text { Ever visited eye } \\
\text { care professional }\end{array}$} & \multicolumn{3}{|c|}{ Mother's History of glasses } & \multicolumn{3}{|c|}{ Father's history of glasses } \\
\hline & & & Yes $(\%)$ & No $(\%)$ & P-value & Yes $(\%)$ & No $(\%)$ & P-value \\
\hline \multirow{6}{*}{ Male } & \multirow{3}{*}{ Yes } & Yes & $10(24.4)$ & $31(75.6)$ & \multirow{3}{*}{0.188} & $11(26.8)$ & $30(73.2)$ & \multirow{3}{*}{0.722} \\
\hline & & No & $2(9.1)$ & $20(90.9)$ & & $5(22.7)$ & $17(77.3)$ & \\
\hline & & Total & $12(19.0)$ & $51(81.0)$ & & $16(25.4)$ & 47 (74.6) & \\
\hline & \multirow{3}{*}{ No } & Yes & $16(34.0)$ & $31(66.0)$ & \multirow{3}{*}{$0.019^{*}$} & $9(19.1)$ & $38(80.9)$ & \multirow{3}{*}{0.245} \\
\hline & & No & $72(18.5)$ & $318(81.5)$ & & $47(12.1)$ & $343(87.9)$ & \\
\hline & & Total & $88(20.1)$ & $349(79.9)$ & & $56(12.8)$ & $381(87.2)$ & \\
\hline \multirow{6}{*}{ Female } & \multirow{3}{*}{ Yes } & Yes & $24(35.3)$ & $44(64.7)$ & \multirow{3}{*}{0.666} & $20(29.4)$ & 48 (70.6) & \multirow{3}{*}{0.256} \\
\hline & & No & $11(29.7)$ & $26(70.3)$ & & $7(18.9)$ & $30(81.1)$ & \\
\hline & & Total & $35(33.3)$ & $70(66.7)$ & & $27(25.7)$ & $78(74.3)$ & \\
\hline & \multirow{3}{*}{ No } & Yes & $16(29.6)$ & $38(70.4)$ & \multirow{3}{*}{0.101} & $19(35.2)$ & $35(64.8)$ & \multirow{3}{*}{$0.001^{*}$} \\
\hline & & No & $65(19.1)$ & $276(80.9)$ & & $53(15.5)$ & $288(84.5)$ & \\
\hline & & Total & $81(20.5)$ & $314(79.5)$ & & $72(18.2)$ & $323(81.8)$ & \\
\hline
\end{tabular}

${ }^{*}$ p-value significant at $\leq 0.05$, using Chi-square test. 
was also found between the visit of the female study subjects to an eye care professional and positive paternal history about the use of spectacles (p-value 0.001). Interestingly, refractive errors were not prevelant in these study participants (Table-I).

The results regarding comparison of the study subjects from public-schools regarding parental history of wearing spectacles and student's visit to eye care professional are presented in Table-II. There was no association but a positive maternal history of the use of spectacles was significantly associated with the ever visit of the male study subjects having refractive errors to an eye care professional (p-value 0.018).

\section{DISCUSSION}

Refractive error is a major public health challenge for the global communities especially in developing countries. ${ }^{14}$ The effected part of the population belongs to various age groups but a significant number of the school children become the victim leading to serious individual, national and international consequences. ${ }^{15}$ According to the report of American Optometrist Association, approximately $25 \%$ of school age children have problems related to vision. ${ }^{9}$ The current study was conducted in the high schools of Lahore which is the second largest city of Pakistan, provincial head quarter and also considered as the educational hub of the country. The findings of the present study conclude prevalence of refractive errors as $20.6 \%$ of the total study subjects. These results are contradictory to the finding of a study from Iraq concluding a prevalence of $33 \% .{ }^{16}$ But the results about types of refractive errors are consistent with the findings of this study as Myopia has been concluded as the major type in both the studies. ${ }^{16}$ However, it is worth mentioning that the abovementioned cross-sectional research was conducted among the students of a medical college. Similarly, the findings regarding prevalence of refractive errors $(20.6 \%)$ are contradictory to the results of another relevant study conducted in school children at Ankara, Turkey concluding a prevalence of $10.8 \% .^{17}$ The findings of the present study are close to the results of another similar research conducted among the students of class $6^{\text {th }}$ to $10^{\text {th }}$ at district Kancheepuram of India concluding the prevalence of refractive errors as $23.8 \% .{ }^{18}$ The results regarding prevalence of refractive errors are similar to the finding of a study conducted among the primary school students of Muzaffarabad concluding a prevalence of $19.6 \% .{ }^{19}$ However the findings are quite different from the results of another school based study conducted at Public sector schools of Bangalore India in which the found prevalence of refractive errors was $10 \%{ }^{20}$ Similarly, the results about the ever visit to an eye care professional for ophthalmic examination are contrary to the finding of above-mentioned study. The current

Table-II: Comparison of Public-school students according to History of wearing spectacles in parents and student's visit to eye care professional.

\begin{tabular}{|c|c|c|c|c|c|c|c|c|}
\hline \multirow[b]{2}{*}{ Gender } & \multirow[b]{2}{*}{$\begin{array}{c}\text { Refractive } \\
\text { error }\end{array}$} & \multirow[b]{2}{*}{$\begin{array}{c}\text { Visited eye care } \\
\text { professional }\end{array}$} & \multicolumn{3}{|c|}{ Mother's History of glasses } & \multicolumn{3}{|c|}{ Father's history of glasses } \\
\hline & & & Yes (\%) & No $(\%)$ & P-value & Yes (\%) & No $(\%)$ & P-value \\
\hline \multirow{6}{*}{ Male } & \multirow{3}{*}{ Yes } & Yes & $34(50.7)$ & 33 (49.3) & \multirow{3}{*}{$0.018^{*}$} & $18(26.90)$ & 49 (73.10) & \multirow{3}{*}{0.362} \\
\hline & & No & $12(27.3)$ & 32 (72.7) & & $8(18.20)$ & $36(81.80)$ & \\
\hline & & Total & $46(41.4)$ & $65(58.6)$ & & $26(23.40)$ & $85(76.60)$ & \\
\hline & \multirow{3}{*}{ No } & Yes & 33 (34.4) & $63(65.6)$ & \multirow{3}{*}{0.707} & $28(29.20)$ & $68(70.80)$ & \multirow{3}{*}{0.095} \\
\hline & & No & $94(32.1)$ & 199 (67.9) & & $61(20.80)$ & $232(79.20)$ & \\
\hline & & Total & 127 (32.6) & $262(67.4)$ & & 89 (22.90) & $300(77.10)$ & \\
\hline \multirow{6}{*}{ Female } & \multirow{3}{*}{ Yes } & Yes & $40(44.9)$ & $49(55.1)$ & \multirow{3}{*}{0.855} & $27(30.30)$ & $62(69.70)$ & \multirow{3}{*}{0.549} \\
\hline & & No & $19(43.2)$ & $25(56.8)$ & & $11(25.00)$ & $33(75.00)$ & \\
\hline & & Total & $59(44.4)$ & $74(55.6)$ & & $38(28.60)$ & $95(71.40)$ & \\
\hline & \multirow{3}{*}{ No } & Yes & $38(42.2)$ & $52(57.8)$ & \multirow{3}{*}{0.073} & $24(26.70)$ & $66(73.30)$ & \multirow{3}{*}{0.690} \\
\hline & & No & 87 (31.4) & $190(68.6)$ & & $80(28.90)$ & $197(71.10)$ & \\
\hline & & Total & $125(34.1)$ & $242(65.9)$ & & $104(28.30)$ & $263(71.70)$ & \\
\hline
\end{tabular}

${ }^{*} \mathrm{p}$-value significant at $\leq 0.05$, using Chi-square test. 
study concludes that $27.8 \%$ of the study subjects ever visited any eye care professional whereas the study conducted in Bangalore found that 10.9\% of the students were ever checked for ophthalmic examination..$^{20}$ A study by Parrey and colleagues from Saudi Arabia has reported the prevalence of $\mathrm{RE}$ to be $45.8 \%$ which is much higher that the prevalence of RE in our study $20.6 \%$. The commonest type of RE in their study was myopia in $24.4 \%$ followed by hyperopia in $11.9 \%$ and simple astigmatism in $9.5 \%$ cases. ${ }^{21}$ However, this research was conducted among adults aged 16 to 39 years.

The focus of this study was to find the association between parental history of spectacles use and any visit of their children to eye care professionals to seek clinical care. It was supposed that the parents with the history of refractive errors and use of required spectacles do have the better access to eye services in terms of knowledge and care. Research studies reveal that the cooperation of parents for ophthalmic examination and subsequent management of the issue is still a major barrier for the school vision programs. ${ }^{22}$ Diverse studies reveal that refraction is associated with genetic factors and positive family history empowers parents to pursue for the care of children. ${ }^{10,23}$

The results of present study, among the private schools about parental history of wearing spectacles and the visit of child to eye care professional conclude that an association was found between the visit of boys to eye care professional and positive maternal history regarding the use of spectacles (p-value 0.019). It is important to mention that these boys were not having the refractive errors as diagnosed during this study. On the other side, an association was found between the visit of girls to an eye care professional and positive paternal history about the use of spectacles (p-value 0.001). The relevant findings among the public-school participants conclude an association between positive maternal history of spectacles and the visit of boys to ophthalmic services for clinical examination ( $\mathrm{p}$-value 0.018 ). It is worth mentioning that these study subjects were having refractive errors. However, there was no association between parental history of spectacles use and ever visit of the child to eye care professional. The findings are quite interesting reflecting the gender based societal practices. Association of maternal history of spectacles use with clinical examination of boys and paternal history with ophthalmic assessment of girls represent the local cultural values. The relevant literature concludes that male genderoriented spending are common in Asian countries like China, India and Pakistan especially for education and health. ${ }^{24}$ However, no differential care seeking for boys and girls was found in a study about the gender-based determination of household decision for health care conducted in Thatta, Pakistan. ${ }^{25}$ This is an initial study about an important question resulting in significant finding. The limitation of this research is the study of association of parental history with the visit of child to eye care professional only and other relevant factors such as parental socio economic and educational status have not been investigated. However, the study provides a baseline for further research in this area.

\section{CONCLUSION}

The study concludes that the gender oriented cultural preferences influence the eye care seeking behavior of the parents for their children. It describes the importance of Women's role as positive maternal history of wearing spectacles is associated with seeking professional care for the children in both public and private school. It reflects that mothers are more concerned for clinical assessment of the children.

\section{Grant Support \& Financial Disclosures: None.}

Note: The article is a part of PhD Public Health Thesis by Author one, conducted at The University of Lahore Pakistan.

\section{REFERENCES}

1. Hashemi H, Fotouhi A, Yekta A, Pakzad R, Ostadimoghaddam H, Khabazkhoob M. Global and regional estimates of prevalence of refractive errors: Systematic review and meta-analysis. J Curr Ophthalmol [Internet]. 2018;30(1):3-22. doi: 10.1016/j. joco.2017.08.009

2. Dandona L, Dandona R. What is the global burden of visual impairment? BMC Med [Internet]. 2006;4(1):6. doi: 10.1186/1741-7015-4-6

3. Pascolini D, Mariotti SP. Global estimates of visual impairment: 2010. Br J Ophthalmol [Internet]. 2012;96(5):614618. doi: 10.1136/bjophthalmol-2011-300539

4. Resnikoff S, Pascolini D, Mariotti SP, Pokharel GP. Global magnitude of visual impairment caused by uncorrected refractive errors in 2004. Bull World Health Organ. 2008;86(1):63-70.

5. World Health Organization. Universal Eye Health: a global action plan 2014-2019 [Internet]. World Health Organization. 2013 [cited 2018 Jan 20]. Available from: http://www.who.int/blindness/AP2014_19_English. pdf?ua $=1$ 
6. Latif MA, Latif MZ, Hussain I, Nizami R, Jamal K. Prevalence of refractive errors in a public school children of Lahore. Pakistan J Med Heal Sci 2014;8(4):1016-1019.

7. Vitale S, Cotch MF, Sperduto RD. Prevalence of visual impairment in the United States. JAMA. 2006;295:2158-2163. doi:10.1001/jama.295.18.2158

8. Keaton BE. To Screen or Not to Screen Parent's Perceptions of Eye Care Prevention for Pre-School Age Children [Internet]. The University of Southern Mississippi; 2016. Available from: https://aquila.usm.edu/cgi/viewcontent. cgi?article $=1381 \&$ context $=$ honors_theses

9. Neville K, Radii E, Velmer G. Improving parental adherence to a failed vision screening referral in the United States. Br J Sch Nurs. 2015;10(3):135-143. doi: 10.12968/ bjsn.2015.10.3.136

10. Ebeigbe JA. Factors influencing eye-care seeking behaviour of parents for their children in Nigeria. Clin Exp Optom. 2016;101(4):560-564. doi: 10.1111/cxo.12506.

11. Sedgwick P. Multistage sampling. BMJ. 2015;351:h4155. doi: 10.1136/bmj.h4155

12. Kevin M. Sullivan. Open Source Statistics for Public Health [Internet]. [cited 2018 May 30]. Available from: http:// www.openepi.com/SampleSize/SSPropor.htm

13. Gilbert C, Minto H, Morjaria P, Khan I. Standard Guidelines for Comprehensive School Eye Health Programs. 2014;iv, 2.

14. Pateras E. Prevalence of refractive errors amongst adults, located at the north suburbs of Athens-Greece. Heal Sci J. 2012;6(1):102-114.

15. Al Wadaani FA, Amin TT, Ali A, Khan AR. Prevalence and pattern of refractive errors among primary school children in Al Hassa, Saudi Arabia. Global J Health Sci. 2012;5:125134. doi:10.5539/gjhs.v5n1p125

16. Ali Salih A. Prevalence and Progression of Refractive Errors Among El-Mustansiriyah Medical Students. EJMO. 2018;2(2):79-83. doi: 10.14744/ ejmo.2017.99609

17. Aydogan U, Eylan OM, Nerkiz P, Doganer YC, Tombus OT, Gokce G, et al. Frequency of refraction errors among schoolage children in Ankara, Turkey: A cross-sectional study. HK J Paediatr [Internet]. 2017;22:209-216. doi: 10.14260/ jemds/2014/2083
18. Aruna S, Thenmozhi P. Screening for refractive error among high school children. Int J Pharma Bio Sci. 2016;7(4):B278B281. doi: 10.22376/ijpbs.2016.7.4.b278-281

19. Awan AR, Jamshed J, Khan MM, Latif Z. Prevalence and causes of visual impairment and blindness among school children in Muzaffarabad, Pakistan. Int J Sci Reports [Internet]. 2018;4(4):93. doi: 10.18203/issn.2454-2156. IntJSciRep20181393

20. Ramachandra K, Gilyaru S, Eregowda A, Yathiraja S. Prevalence of refractive error and the eye morbidity in school children in Bangalore, India. Int J Contemp Pediatr. 2016,3:138-141.

21. Parrey MUR, Elmorsy E. Prevalence and pattern of refractive errors among Saudi adults. Pak J Med Sci. 2019;35(2):394398. doi: 10.12669 / pjms.35.2.648

22. Chu R, Huang K, Barnhardt C, Chen A. The Effect of an On-Site Vision Examination on Adherence to Vision Screening Recommendations. J Sch Nurs. 2015;31(2):84-90. doi: $10.1177 / 1059840514524599$

23. Pärssinen $\mathrm{O}$, Kauppinen M. What is the influence of parents' myopia on their children's myopic progression? A 22-year follow-up study. Acta Ophthalmol. 2016;94(6):579-585. doi: 10.1111/aos.13043

24. Course L, Commons S. Gender-based parental investments and intergenerational support Son Biased Investments and Old Age Support * [Internet]. Singapore; 2017. Available from: http://ink.library.smu.edu.sg/soe_research/2065

25. Nuruddin R, Hadden WC, Petersen MR, Lim MK. Does child gender determine household decision for health care in rural Thatta, Pakistan? J Public Health (Bangkok). 2009;31(3):389-397. doi: 10.1093/pubmed/fdp038

\section{Authors' Contribution:}

MZL conceived, designed, collected data, analysis and initial write up.

MAK \& SA statistical analysis, interpretation, edited the manuscript \& reviewed.

SAG reviewed and finalized the article.
Authors:

1. Dr. Muhammad Zahid Latif, MBBS, MPH, MME, PhD (RS) Department of Community Medicine \& Medical Education, Azra Naheed Medical College,

The Superior University Lahore, Pakistan.

2. Dr. Muhammad Athar Khan, MPH (USA), PhD (USA), Institute of Public Health,

3. Dr. Saira Afzal MBBS, MPhil, MCPS, FCPS, PhD, Dean Faculty of Community Medicine \& Public Health, King Edward Medical University, Lahore, Pakistan.

4. Dr. Syed Amir Gilani, MBBS, DMRD, PhD, Dean Faculty of Allied Health Sciences,

2,4: The University of Lahore, Lahore, Pakistan. 